\section{Tratado de Neurología Clínica}

\section{Editores:}

Editorial:
Jorge Nogales-Gaete Archibaldo Donoso S. Renato J. Verdugo L. Sociedad deN eurología, Psiquiatría y N eurocirugía, Chile y Ediciones Universitaria, 2005 728 páginas
El origen de la neurología moderna como especialidad independiente dentro de la medicina occidental se remonta al período 1850-1890, con el protagonismo directo y las publicaciones de distinguidos clínicos como Charcot, Babinski, Duchenne, Romberg, Henoch, Westphal, W ernicke, Jackson, Wilson, Gowers, Holmes, Erb, BrownSequard, Parinaud, Oppenheim y Broca, entre otros. Como hito fundacional organizacional y formativo podemos destacar la creación de la primera cátedra de Enfermedades N erviosas en 1882 en la Facultad de M edicina de Paris, que fue dirigida por Charcot.

A pesar que los mecanismos patogénicos relacionados con el compromiso del sistema nervioso (SN) son comunes con los que ocurren en otros parénquimas, ha sido la conspicua complejidad y relevancia de la topografía de los centros y redes nerviosas (anatómica y química) y su expresión clínica las que han favorecido la necesidad e identidad de esta especialidad.

Por otro lado, los avances en estudios de neuroimágenes del sistema nervioso central y más reciente del periférico, la determinación genética de las enfermedades degenerativas y metabólicas y sus fundamentos en la biología molecular, las nuevas terapias en epilepsia, esclerosis múltiple, enfermedades extrapiramidales, las propuestas integrales de manejo de las enfermedades cerebro- vasculares, incluyendo tratamientos endovasculares y unidades de neurointensivo, han generado un explosivo aumento de los conocimientos incluidos en la neurología.

Por estos motivos, elaborar un Tratado de Neurología Clínica en español en una época como la actual es una compleja tarea, ya que debe dar cuenta en forma balanceada tanto de estos avances como de aquellos conocimientos o re flexiones de una neurología más clásica y asentada.

Para nosotros constituye un gran honor escribir el prólogo de este Tratado de Neurología Clínica. Esta obra tiene la característica de constituir un tratado de la especialidad, destinada a ser un importante texto de consulta no sólo para el neurólogo, sino que también para el médico general y otros especialistas, además de ser un adecuado texto de consulta para los alumnos de las escuelas de medicina. Esta particularidad se deriva del doble enfoque que tiene el texto. Por una parte incluye una aproximación al paciente desde el punto de vista de las manifestaciones clínicas y, por otra, la descripción actualizada de cuadros clínicos específicos y sus tratamientos. Además, los contenidos están adaptados a la realidad y diversidad epidemiológica de Latinoamérica, lo que amplía su proyección a este ámbito.

En la década de 1930 vio la luz la valiosa obra en dos volúmenes de Barraquer Ferré, completísima y con el respaldo de una sólida experiencia personal, y en la década de 1950 el notable volumen de Enfermedades del Sistema Nervioso de la Colección de Patología M édica de Pedro Pons y colaboradores. Casi contemporáneamente aparecía en Argentina el Tratado de Litter y Wexselblatt, con fuerte influencia de la Escuela Clásica Francesa y que gozó de popularidad en la enseñanza de pregrado en los países del cono sur. En los años siguientes se publicaron o se reeditaron múltiples tratados de grandes maestros europeos, tales como Wilson, Brain, Scheid, Walton y los estadounidenses Adams y Víctor (Principios de la Neurología) y Merritt (Texto de Neurología), reeditado con múltiples autores por 
Rowland. Estos textos de formato extenso pero en un volumen, fueron seguidos de obras aún más acabadas, a saber: Diseases of the N ervous System and Clinical Neurobiology de Asbury, McKhan y $\mathrm{McD}$ onald y Neurology in Clinical Practice de Bradley, Daroff, Fenichel y Marsden, que incorpora acceso al texto por CD e Internet, transformándose en un compañero permanente en la práctica profesional de muchos neurólogos. Recientemente Zarranz en España y M icheli en Argentina han incorporado nuevas obras en español.

La existencia y categoría de las obras mencionadas da especial mérito al presente Tratado con aportes de 104 autores y coautores, liderados por el editor jefe Profesor Dr. Jorge Nogales-Gaete y los editores asociados Profesores Dres. Archibaldo Donoso y Renato Verdugo, con cuatro editores asistentes quienes han sabido convocar y liderar destacados autores, así como seleccionar y editar contenidos e información, dándole en cuanto es posible un estilo unitario y de fluida lectura.

El texto está estructurado en dos secciones. La primera consta de cinco módulos y 26 capítulos que abordan los síndromes neurológicos, mereciendo especial mención capítulos como estado vegetativo persistente y muerte encefálica, que dan cuenta de dos realidades emergentes, ligadas a la supervivencia (gracias a las Unidades de Cuidados Intensivos) de pacientes gravemente dañados y a la necesidad de conciliar la atención de pacientes gravísimos con los indispensables programas de donación de órganos y trasplantes. En todos esos aspectos la información es muy satisfactoria.

La segunda sección, que abarca el grueso de la obra, está constituida por el desarrollo de las enfermedades neurológicas en 13 módulos y 62 capítulos. Su revisión evidencia exposiciones completas y con alta representatividad de las afecciones de mayor prevalencia, tales como enfermedad cerebrovascular, neurotrauma, neuroinfectología, entidades degenerativas corticales, extrapiramidales y cerebelosas, afecciones neuromusculares, epilepsias y cefaleas.
Dentro de los numerosos méritos de este Tratado quisiéramos destacar que el repertorio temático es muy adecuado, considerando que en un solo volumen es imposible incluir toda la neurología, con una profundidad y extensión que dé satisfacción universal. Este libro reúne, en un balance equilibrado, patologías relacionadas al mundo del subdesarrollo -como las parasitosis del sistema nervioso- y aquellas que están mayormente representadas en países desarrollados, como son las alteraciones genéticas y degenerativas. Además están incluidas Ias lesiones traumáticas tanto agudas como sus secuelas, que constituyen una epidemia lamentablemente creciente y transversal a todos los niveles de desarrollo. Por otro lado, tiene capítulos que no son frecuentes de encontrar en otros textos, como el impacto neurológico de la marea roja, los disbarismos del buceo y aspectos éticos de la relación médico-paciente, entre otros.

El desarrollo de todos los temas es completo, razonablemente amplio y refleja tanto la experiencia y trayectoria de los autores como la revisión de las referencias más importantes y actualizadas de la literatura. Se logró reunir autores de diferentes lugares del país, realidades tecnológicas y escuelas formadoras, con práctica profesional en centros de diverso carácter: universidades, hospitales, clínicas privadas, a fin que la visión de las diferentes materias que abarca fueran enfrentadas con una mirada amplia. Esta diversidad de aproximación favorece sin duda la proyección latinoamericana del texto, aun cuando llama la atención la similitud de criterios para enfrentar aspectos fundamentales del diagnóstico y del tratamiento a través del país.

En la mayoría de los capítulos se evitó un exceso de referencias, a través de un mayor esfuerzo intelectual, como buscar las más significativas, completas y recientes. Algunos capítulos contienen buenas ilustraciones y fotografías de aspectos semiológicos como neuroimágenes, lo cual es muy útil para complementar la lectura.

Este Tratado, que es sin duda un paso notable y pionero en obras de su tipo a nivel nacional e incluso latinoamericano, merece recomendarse 
con entusiasmo y orgullo como una obra de consulta tanto en la enseñanza de pregrado como, fundamentalmente, en el postgrado de la neurología propiamente tal, como de aquellas otras especialidades que incluyen una asignatura de neu- rología en su plan formativo, como son: neurocirugía, psiquiatría, medicina interna, medicina familiar, medicina de urgencia, medicina física y rehabilitación, traumatología y práctica médica en general.

Camilo Arriagada R.

Profesor de Neurología, Universidad de Chile

JaIme COURT L.

Profesor de Neurología, Pontificia Universidad Católica de Chile

Fernando Novoa $S$.

Profesor de Neurología, Universidad de Valparaíso

Maestros de la Neurología Sociedad de Neurología, Psiquiatría y Neurocirugía, Chile

(Prólogo del libro, reproducido con autorización del editor) 